\title{
EDITORIAL: ENTRE O VÍRUS E O ESTIGMA
}

Esta edição dos Cadernos do CEAS vem à luz, quando o Brasil e as Américas se encontram nas trevas. Aqui e alhures, suas lideranças estão mergulhados no desgoverno, de braços dados com o neofascismo, ainda que com exceções nacionais; mas, ao Norte e ao Sul, ameaçados por guerra civil, exacerbação do racismo, xenofobismo e genocídios.

Isso, genocídios no plural, porque além da covid-19, que em 2020 ceifa vidas às centenas de milhares no Continente, apenas aparentemente sem olhar a quem, as ações e omissões dos Estados avançam produzindo o secular extermínio dos povos indígenas da grande Amazônia, dos afrodescendentes e dos povos originários. Vítimas prioritárias da violência, esses povos e culturas agora estão submetidos ao efeito de um velho instrumento colonial, um vírus, o novel SARS-CoV-2. Todavia, o tristemente popular coronavírus, que devasta prioritariamente aos negros, amazônidas e aos mais pobres de qualquer etnia, amontoados nas favelas urbanas e rurais das Américas, não age sozinho. Conta com a política genocida de vários Estados da imensa América.

Uma clara necropolítica que passa por diversos caminhos, desde a secular violência policial, a segregação sócio-étnico-espacial, a destruição de sistemas de saúde públicas e universais, a negativa de acesso à educação e demais direitos sociais até a super-exploração do trabalho e da natureza.

Os Cadernos do CEAS, que em sua trajetória cinquentenária dedica-se à análise crítica dessas questões e tantas outras a essas correlatas, como a de auscultar movimentos e iniciativas que apontam para uma necessária transformação desse status quo, na presente edição tratará de quatro desses caminhos mencionados.

O primeiro, das questões ambientais, será abordado através das iniciativas da Igreja Católica e do Papa Francisco, quanto ao importante processo de conversão ecológica e pastoral consubstanciado no Sínodo da Amazônia e conta com duas colaborações. No segundo caminho, três artigos retomam temas importantes para repensar as relações sociais, a governança democrática e os modos de distribuição e produção de alimentos, especialmente, em tempos de colapso do modo de produção capitalista, envolto em sua mais profunda crise desde os anos de 1930. Temas caros à trajetória da economia social e solidária, 
como o caráter democrático das iniciativas sociopolíticas da economia organizada a partir dos movimentos sociais e dos camponeses são aqui refletidos por uma plêiade de autores, tão qualificados academicamente, quanto comprometidos com uma sociedade livre da opressão e dos desmandos do capital. Um antídoto contra a necropolítica, poderíamos assim definir o caminho percorrido por esses textos.

No terceiro caminho dos textos ora publicados serão discutidos os impactos da segregação sócio espacial nas desigualdades raciais presentes na sociedade brasileira. E encerrando os percursos dessa edição, a política educacional será refletida em dois artigos que fazem uma clivagem geracional do tema, um pela formação profissional de jovens, outro, pela educação continuada e permanente de adultos.

Abre a edição, o texto de Ima Célia Guimarães Vieira (Museu Paraense Emilio Goeldi - MPEG; Márcia Maria de Oliveira (Universidade Federal de Roraima - UFRR) e Raimundo Posidônio Carrera da Mata (Faculdade Católica de Belém - FACBEL) abordando, em "Os dez mandamentos do Sínodo Especial para a Amazônia", os trabalhos sinodais realizados no Vaticano, em outubro de 2019. As autoras apresentam uma breve descrição da pedra de toque dessa iniciativa, a fundamental encíclica papal, Laudato Si; os principais resultados do Sínodo e os seus Dez Mandamentos, considerados muito relevantes, porque integrariam a voz da Amazônia com a voz e o sentimento dos participantes do Sínodo.

Ainda no tema Igreja - Amazônia, o cientista político Joviniano S. Carvalho Neto (UFBA), em "O Sínodo da Amazônia - Um acontecimento definidor" discute o projeto da Igreja Católica para o Sínodo, a cobertura da mídia impressa sobre os vários momentos do mesmo, e a posição final do Papa Francisco, manifesta em documento oficial da Cúria, que incorpora o Sínodo na política papal, como o novo modelo civilizatório e de conversão da própria Igreja.

Anete B. L. Ivo, na sequência, examina as origens e os limites da noção de governança a partir de contextos distintos, que vão do neoliberalismo às tendências contra-hegemônicas, marcadas por lutas e demandas da cidadania. Em "A noção de governança: Uma mesocategoria da ação coletiva", Anete situa dialeticamente a noção de governança ante as práticas discursivas e conceituais, mas apontando sempre para um espaço definido. Assim, a categoria "território(s)" adquire lugar central na reflexão desta socióloga, que enfatiza, para além do caráter polissêmico da ação coletiva, a existência de conflitos cognitivos sobre a regulação social nos territórios, evidenciando que arranjos de governança expressam 
relações de poder, cuja dinâmica não se restringe exclusivamente ao Estado, mas envolve forças sociais em conflito, mediadas por processos de construção da hegemonia na política.

Ainda que não tenha sido escrito em diálogo com o texto anterior, a abordagem de Luiz Inácio Gaiger (Unisinos) em "Economia solidária, ativismo sociopolítico e democracia", discute a ação coletiva das organizações e representantes da economia social solidária. Este autor examina a contribuição da Economia Solidária para os processos democráticos no Brasil, indicando a sua presença e atuação em movimentos e organizações de caráter social e político, tendo como fonte a base de dados do Sistema Nacional de Informações sobre a Economia Solidária no Brasil. Aborda ainda as relações entre os níveis de ativismo sociopolítico e as formas de gestão participativa adotada internamente pelos empreendimentos de economia solidária. Por fim, analisa os traços distintivos da liderança e seu possível distanciamento daqueles indivíduos cuja associação constitui a base dos empreendimentos.

Portanto, usando o conceito de ativismo sociopolítico e não o de governança examina-se a ação coletiva dos setores das classes populares e sua interface com a questão democrática, para a qual aportam, como conclui o autor, uma importante contribuição.

Mantendo o foco no setor popular, mas agora direcionado aos camponeses e sua relação com o mercado local, Bruna Saldanha Vogelei e Ezequiel Redin, em "As famílias rurais nas feiras livres: espaço de produção, comercialização e consumo" refletem sobre os motivos que conduzem as famílias rurais a comercializar seus produtos na feira livre.

A partir de uma pesquisa sobre as práticas de produção, relações de comercialização e consumo das famílias feirantes de Santa Maria, RS, os autores demostram o perfil socioeconômico dessas famílias, bem como as razões de escolherem as feiras livres como espaço principal de comercialização dos seus produtos. Nesse sentido, este mercado local constitui-se em um canal flexível e pouco burocrático, onde conseguem um maior preço pelo produto, quando comparado ao que obteriam no mercado tradicional.

Seguindo a linha de estudos sobre a agricultura familiar camponesa, o artigo indica que as famílias estudadas, dadas as restrições no tamanho das suas propriedades, têm na comercialização direta realizada na feira livre, uma renda residual relevante, representando esse canal um vetor importante para a reprodução econômica dessas famílias e também para o desenvolvimento rural do município de Santa Maria, RS. 
O terceiro caminho percorrido por esta edição nos leva de volta ao enredo da necropolítica. Desta feita, coube a sempre precisa Inaiá Maria Moreira de Carvalho, em "Desigualdades raciais no espaço urbano" discutir como os padrões e os impactos da segregação sócio espacial se articulam com as desigualdades raciais na sociedade brasileira. A socióloga usou para tanto dados dos Censos demográficos, das PNADS e de algumas pesquisas empíricas realizadas em Salvador, Bahia, a quarta maior cidade do país e onde os negros representam a absoluta maioria da população. Seu trabalho explicita como os padrões de segregação se articulam com as desigualdades raciais e como a concentração de moradores pobres e majoritariamente negros em áreas homogêneas, precárias e desassistidas agrava a sua despossessão e a sua vulnerabilidade, ressaltando que a apropriação diferenciada do território urbano também contribui para a persistência e para o agravamento das desigualdades raciais no Brasil.

Esta edição chega ao seu quarto e último caminho, arrodeada por um estigma ministerial, aqui não discutido, mas que a simples menção ao tema do artigo invoca. Em a "Educação de adultos como processo continuado permanente: Um estudo de casos com idosos", como diz o próprio título, Alcides Alves de Souza Filho, Antonio Amorim e Kátia Siqueira de Freitas tratam da educação da pessoa idosa; práticas e processos socioeducativos que materializam o programa voltado à Política Pública na perspectiva de educação escolar e social. Os autores apontam a importância da educação continuada e permanente na vida do idoso, analisando os aspectos que concretizam a ressignificação da vida e reconstrução de si nessa fase da vida. Chamam á atenção também para a vivência, aprendizagens e saberes no ambiente de uma Universidade Aberta à Terceira Idade (UATI), bem como para a importância da educação ao longo da vida.

No último artigo da edição, todavia, o estigma que ronda a Educação ameaça tomar forma concreta. Em "Os ataques à Educação profissional na atualidade", Nívia Barreto dos Anjos objetiva demonstrar que a Rede Federal de Educação Profissional, por protagonizar um projeto político pedagógico inovador, incomoda certos atores da hegemonia capitalista e por isso é alvo de variados ataques nos tempos atuais. A autora afirma que a Rede IF aponta para o desenvolvimento da ciência, da educação, da cultura e do pensamento crítico. E a isso credita a intenção do neoliberalismo de "colocar em xeque" a existência e a funcionalidade dos Institutos Federais como espaços de produção e socialização do conhecimento. O seu texto reafirma a Política de Educação Profissional como um direito social que precisa ser 
fortalecido para enfrentar os ditames e a brutalidade do capital, direito este fruto de muitas lutas sociais, e que hoje incomoda aos detentores do capital, por sinalizar uma cidadania crítica e uma educação socialmente referenciada.

Percorridos esses caminhos, a $249^{\text {a }}$ edição inclui também, a Resenha do livro de SASSEN, Saskia: Expulsões. Brutalidade e complexidade na economia global. Tradução de Angélica Freitas. $1^{\text {a }}$ ed. Rio de Janeiro/São Paulo: Paz e Terra. 2016. 336 p., da lavra de Márcia Esteves de Calazans e Emília da Silva Piñeiro, sob o título "A lógica das expulsões por Saskia Sassen".

Finalmente, na seção Documentos, esta edição disponibiliza a versão completa da Exortação apostólica pós-sinodal QUERIDA AMAZÓNIA: do Santo Padre Francisco ao povo de Deus e a todas as pessoas de boa vontade. Essa decisão editorial decorre da importância deste documento que, ao propor um novo modelo civilizatório para o mundo, antagônico àquele que resultou na atual crise mundial econômica, social e ambiental e sanitária, pode tornar-se um instrumento de luta à disposição de todos os contra poderes engajados na construção de uma sociedade mais justa, fundada na liberdade e na fraternidade entre os homens e mulheres e na compreensão de que a proteção à terra em que vivemos é parte da proteção à vida humana e a todas as formas de vida.

Os Cadernos do CEAS convidam a todos à leitura e a reforçarem os caminhos democráticos para o país e para o mundo.

Joaci de S. Cunha, coeditor. 